\title{
Remoção de Microcystis sp. e microcistinas de águas no tratamento de ciclo completo associado à adsorção em carvão ativado visando abastecimento público \\ Microcystis sp. and microcystins removal in the full cycle treatment associated with adsorption on activated carbon for public supply \\ Data de entrada: 01/03/2018 \\ Data de aprovação: 20/07/2018
}

Amanda Alcaide Francisco Fukumoto ${ }^{1 *}$ | Josemarque Lima da Rosa ${ }^{2}$ |

Vilson Gomes da Assunção Júnior ${ }^{3}$ | Emília Kiyomi Kuroda'

ORCID ID

Fukumoto, A.A.F (D) https://orcid.org/0000-0003-0406-0644

Rosa, J. L (iD https://orcid.org/0000-0002-3612-7957
DOI: https://doi.org/10.36659/dae.2020.018

Júnior, V.G.A (ID) https://orcid.org/0000-0002-0114-4351

Kuroda, E. K (1D) https://orcid.org/0000-0001-8678-5619

\section{Resumo}

O despejo inadequado de efluentes em mananciais de abastecimento pode acarretar a presença de cianobactérias toxigênicas produtoras de microcistinas (MCs) nocivas à saúde. Desse modo, este trabalho teve por objetivo avaliar a eficiência do tratamento por ciclo completo, em escala de bancada, associado ou não à adsorção em carvão ativado na forma pulverizada - CAP ou granular - CAG, para água de estudo com densidade celular da ordem de $10^{5} \mathrm{cel} \mathrm{mL}^{-1}$ de Microcystis sp. e concentração aproximada de $20 \mu \mathrm{g} \mathrm{L}^{-1}$ de MCs. Para tanto foram utilizados o hidróxi-cloreto de polialumínio como coagulante, 14 tipos de CAP e 7 de CAG. Os resultados indicaram a necessidade de associação da adsorção em carvão ativado ao tratamento por ciclo completo para produção de água tratada com valores inferiores a $1,0 \mu \mathrm{g} \mathrm{L}^{-1}$ de MCs, valor máximo permitido no Anexo XX da Portaria de Consolidação $n^{\circ}$ 5/2017.

Palavras-chave: Tratamento de água. Cianotoxinas. Carvão ativado.

\section{Abstract}

The inadequate disposal of effluents in supply sources may lead to the presence of toxigenic cyanobacteria producing microcystins - MCs, which are harmful to health. Thus, this study aimed to evaluate the efficiency of the full cycle treatment, in the bench scale, associated or not to adsorption on activated carbon in the pulverized form - PAC or granular - GAC, for study water with cell density of $10^{5}$ cell $\mathrm{mL}^{-1}$ of Microcystis sp. and approximate concentration of $20 \mathrm{~g} \mathrm{~L}^{-1}$ of MCs. For this, the poly aluminium chloride was used as the coagulant, 14 types of PACs, and 7 of GACs. The results indicated the need to associate adsorption in activated carbon to the treatment by full cycle treatment for the production of treated water with values lower than $1.0 \mu \mathrm{g} \mathrm{L}^{-1}$ of MCs, maximum value allowed by Ordinance 5/2017-appendix XX.

Keywords: Water treatment. Cyanotoxins. Activated carbon.

\footnotetext{
${ }^{1}$ UEL - Universidade Estadual de Londrina - Departamento de Construção Civil do Centro de Tecnologia e Urbanismo. Londrina - PR - Brasil. ${ }^{2}$ IFPR - Instituto Federal do Paraná. Campus União da Vitória - PR - Brasil.

${ }^{3}$ Unifil - Centro Universitário Filadélfia - Departamento de Engenharia Civil. Londrina - PR - Brasil.

* Autor correspondente: amandaalcaide_fayahoo.com.br.
} 


\section{INTRODUÇÃO}

A contaminação de mananciais utilizados para abastecimento de água é, em grande parte, proveniente dos rejeitos produzidos pelas atividades humanas. O despejo de efluentes domésticos, industriais e agrícolas em corpos hídricos, sob determinadas condições ambientais como temperatura, incidência de luz e velocidade dos ventos, pode favorecer a formação de florações ou "blooms" de cianobactérias.

As cianobactérias se destacam por estarem associadas à presença de metabólitos secundários, que conferem sabor e odor desagradáveis à água, e, especialmente, às cianotoxinas, que podem acarretar diversos prejuízos à saúde humana e de animais aquáticos. A ocorrência, distribuição e frequência de cianobactérias tóxicas indicam elevada recorrência do gênero Microcystis e da hepatoxina peptídica cíclica microcistinas - MCs em vários países (CHORUS; BARTRAM, 1999; FUNASA, 2003; SANT'ANNA et al., 2006; SORLINI, GIALDINI, COLLIVIGNARELLI, 2013; CHATZIEFTHIMIOU, 2016; HARKE, 2016).

A presença de MCs tem ocasionado diversos problemas às estações de tratamento de água ETAs, em relação à qualidade da água distribuída e, invariavelmente, requer a adoção de técnicas específicas para remoção desses compostos, resultando no aumento dos custos associados ao tratamento. Isso ocorre uma vez que, segundo diversos autores, o tratamento por ciclo completo, comumente empregado nas ETAs, pode ser eficiente para remoção de células intactas, mas insuficiente para remoção de MCs extracelulares aos níveis de segurança à saúde (CHORUS; BARTRAM, 1999; BETTINA, et al., 2000; DRIKAS et al., 2001; KURODA et al., 2005; TEIXEIRA; ROSA, 2007; SILVA et al., 2012; MOHAMED et al., 2015; PARK et al., 2017).

Para evitar o consumo de água contendo MCs, a água disponibilizada para o abastecimento pú- blico deve atender aos padrões de potabilidade exigidos pelo Ministério da Saúde, por meio do Anexo XX da Portaria de Consolidação n ${ }^{\circ}$ 5/2017, no qual o valor máximo permitido de MCs totais é de 1,0 $\mathrm{g} \mathrm{L}^{-1}$. Dessa forma, há necessidade de buscar tratamentos complementares ao ciclo completo para a remoção de MCs extracelulares, como a adsorção em carvão ativado - CA, na forma pulverizada - CAP ou granular - CAG.

O CA é um tipo de material carbonáceo, caracterizado por possuir área superficial interna elevada e porosidade altamente desenvolvida, de forma a possibilitar a adsorção de moléculas em fase líquida e gasosa (COUTINHO et al., 2000; RUIZ et al., 2010; DELGADO et al., 2012). Estudos relacionados à adsorção de MCs demonstraram que o emprego de CAs é eficiente na remoção de MCs, com destaque aos CAs com maior volume de mesoporos, uma vez que a abertura dos poros de 2 a $50 \mathrm{~nm}$ favorece a remoção dessas moléculas, que apresentam tamanho médio estimado entre 1,2 a 2,6 nm e massa molecular entre 950 a 1050 Da (DONATI et al., 1994; WARHURST, MCCONNACHIE, POLLARD, 1997; PENDLETON, SCHUMANN, WONG, 2001).

Devido à intermitência dos eventos de floração de cianobactérias, a flexibilização da utilização de CAP, por não requerer unidade física adicional de tratamento e poder ser aplicado com razoável simplicidade antes ou imediatamente após a coagulação, tem-se apresentado como alternativa técnica promissora para remoção de MCs extracelulares e também de clarificação da água, favorecendo a sedimentação e resultando em carreiras de filtração mais prolongadas (DE JúLIO et al., 2010; ZAMYADI, et al., 2012; LI et al., 2015). Já o CAG requer, para uso, a construção de uma unidade física adicional de tratamento e é comumente adotado em países desenvolvidos como polimento final, após a etapa de filtração para remoção de MCs extracelulares e também 
de outros compostos que estejam dissolvidos na água (DI BERNADO, DANTAS e VOLTAN, 2017).

Diante do exposto, este trabalho teve como objetivo investigar a eficiência da técnica de ciclo completo, com as etapas de coagulação, floculação, sedimentação e filtração em areia, com e sem associação da adsorção em CAP e em CAG, em escala de bancada, de forma a garantir a produção de água segura e com qualidade compatível com o Anexo XX da Portaria de Consolidação $n^{\circ} 5 / 2017$, em relação às MCs totais.

\section{METODOLOGIA}

\subsection{Preparação das águas de estudo}

Para a preparação das águas de estudo foi utilizada a cepa toxigênica de Microcystis sp. - TAC95, selecionada por produzir elevadas concentrações de MC-LR (da ordem de $3000 \mu \mathrm{g} \mathrm{L}^{-1}$ ) (KURIAMA, 2012). Para tanto, a cepa foi mantida por meio de inoculações quinzenais a $10 \%(v v-1)$ em meio ASM-1 (GORHAM, 1964) estéril (autoclavado a $121^{\circ} \mathrm{C}$ durante $20 \mathrm{~min}$ ), sendo as culturas submetidas à temperatura de $25^{\circ} \mathrm{C}$ e iluminação de $35 \mu \varepsilon \mathrm{m}^{-2} \mathrm{~s}^{-1}$, com fotoperíodo de $12 \mathrm{~h} \mathrm{~d}^{-1}$ e agitação manual diária.

Para obtenção dos extratos com MCs, $20 \mathrm{~L}$ de cultura, em fase final da curva exponencial de crescimento, foram centrifugadas a $1521 \mathrm{~g}$ por 20 minutos, para obtenção de biovolume, sendo este congelado a $-20^{\circ} \mathrm{C}$ e submetido a 3 séries de congelamento/descongelamento, liofilizado, macerado e ressuspenso em água ultrapura, constituindo o extrato com MCs. Por fim, o extrato foi filtrado em membrana de fibra de vidro, com porosidade média de $0,2 \mu \mathrm{m}$ e armazenado a $-20^{\circ} \mathrm{C}$.

Em seguida, utilizando-se água potável desclorada ( $\mathrm{pH}$ de 6,9 e turbidez de 0,52 NTU), cultura de Microcystis sp. e extrato com MCs, foram preparadas as águas de estudo - AEs: AE1 com concentração da ordem de $20 \mu \mathrm{g} \mathrm{L}^{-1}$ de MCs extracelulares e a AE2 com concentração da ordem de $20 \mu \mathrm{g} \mathrm{L}^{-1}$ de MCs extracelulares e densidade celular de $10^{5}$ cel $\mathrm{mL}^{-1}$ de Microcystis sp..

\subsection{Amostragem e caracterização preliminar de CAPs e CAGs}

Foram adquiridas amostras de CAPs e CAGs disponíveis comercialmente no mercado nacional e internacional, com características diversificadas em relação à origem, matéria prima, método de ativação e propriedades físico-químicas. Após a amostragem dos 14 CAPs e 7 CAGs, os mesmos foram caracterizados de acordo com o Número de lodo - NI e Índice de Fenol - IF, segundo as NBRs 12073/1991 - MB 3410 e 12074/1991 MB 3411, respectivamente, e Índice de Azul de Metileno - IAM, conforme a JAPANESE INDUSTRIAL STANDARD - JIS K 1474/2014.

\subsection{Seleção de CAPs e CAGs}

Para o preparo dos CAPs, os mesmos foram previamente secos em estufa a $103^{\circ} \mathrm{C}$ por $24 \mathrm{~h}$. Em seguida, as massas de CAPs foram adicionadas em tampão fosfato de Sorensen $(\mathrm{pH}=7,0)$, conforme Morita e Assumpção (2007), a fim de evitar alterações significativas nos valores de $\mathrm{pH}$ e influenciar na eficiência do processo adsortivo. Já os CAGs foram previamente secos em estufa a $103^{\circ} \mathrm{C}$ por $24 \mathrm{~h}$, pesados e imersos em água ultrapura, sob agitação de $15 \mathrm{rpm}$ em mesa agitadora, por $24 \mathrm{~h}$, para saturação dos poros de adsorção.

Para seleção dos CAPs e CAGs de maior capacidade adsortiva para MCs foi utilizada a AE1 e os seguintes experimentos:

- Adsorção em CAP: realizado em frascos de vidro com volume reacional de $50 \mathrm{~mL}$, dosagem de CAP de $25 \mathrm{mg} \mathrm{L}^{-1}$, tempo de contato de $60 \mathrm{mi}-$ 
nutos, sob agitação de $150 \mathrm{rpm}$, temperatura de $25^{\circ} \mathrm{C} \pm 1{ }^{\circ} \mathrm{C}$, em mesa agitadora;

- Adsorção em CAG: realizado em escoamento contínuo com auxílio de bomba peristáltica e duração de 24 h, em filtros de carvão ativado granular - FCAGs com altura de CAG de $9,0 \mathrm{~cm}$, vazão de alimentação constante de $0,80 \mathrm{~mL} \mathrm{~min}^{-1}$ para cada filtro, resultando em tempo médio de contato de 20 minutos, conforme Kawahigashi et al. (2014).

A seleção dos CAPs e CAGs mais eficientes foi realizada em função das concentrações residuais de MCs nas amostras, previamente filtradas em membrada com porosidade média de 0,45 $\mu \mathrm{m}$, sendo estas analisadas pelo método de imunoensaio enzyme-linked immunosorbent assay (ELISA) (kits de Beacon Analytical Systems Inc.) com limite de quantificação - LQ de 0,12 $\mathrm{g} \mathrm{L}^{-1}$ de MCs.

\subsection{Determinação das condições adsortivas para aplicação do CAP selecionado}

Para determinar as condições adsortivas de aplicação mais adequadas, em relação à dosagem de CAP e ao tempo de contato empregados, foi utilizada a AE2, a fim de simular uma situação mais aproximada de manancial natural eutrofizado. Dessa forma, foram empregadas as dosagens do CAP selecionado de 5, 10, 25, 30, 40 e $50 \mathrm{mg} \mathrm{L}^{-1}$ e tempos de contato de 15, 30, 60 e $120 \mathrm{~min}$. As demais condições experimentais foram as mesmas empregadas no experimento para a seleção de CAP. Entretanto, devido à presença de células, os frascos de reação foram expostos à luminosidade de $35 \mu \varepsilon \mathrm{m}^{-2} \mathrm{~s}^{-1}$, a fim de manter as condições de cultivo.

A dosagem de CAP foi selecionada considerando a condição que atendeu ao valor máximo permitido de 1,0 $\mathrm{g} \mathrm{L}^{-1}$, estabelecido pelo Anexo XX da Portaria de Consolidação $n^{\circ}$ 5/2017. Para avaliar o efeito escala sobre as condições de adsorção obtidas no experimento com volume reacional de $50 \mathrm{~mL}$, as condições de adsorção selecionadas foram reproduzidas em reatores estáticos / equipamento jarteste com volume reacional de $2 \mathrm{~L}$.

\subsection{Tratamento por ciclo completo}

Após determinar a condição adsortiva mais adequada para aplicação do CAP nacional selecionado, foram realizados ensaios em escala de bancada, em equipamento Jarteste, simulando as etapas de coagulação, floculação e sedimentação, utilizando-se a AE2 e o hidróxi-cloreto de polialumínio - PAC, como coagulante. Para ajuste do $\mathrm{pH}$ foram utilizados o hidróxido de sódio, como alcalinizante e o ácido clorídrico, como acidificante.

A condição de coagulação foi determinada a partir da melhor relação custo $x$ benefício, ou seja, foi selecionada a condição (dosagem de alumínio e $\mathrm{pH}$ ) que apresentasse elevada remoção de turbidez e de células de Microcystis sp. para o menor volume de coagulante. Dessa forma, considerando dados da literatura (KURODA, DI BERNARDO, 2006; FONSECA, 2014), foram empregadas dosagens de 2,0; 4,0 e 6,0 $\mathrm{mg} \mathrm{L}^{-1}$ de alumínio - Al para valores de $\mathrm{pH}$ de 6,$0 ; 6,5 ; 6,7$ e 7,0 e parâmetros operacionais apresentados na Tabela 1.

Tabela 1 - Parâmetros operacionais utilizados para simulação do ciclo completo.

\begin{tabular}{|c|c|}
\hline $\begin{array}{c}\text { Tempo de mistura rápida - Tmr } \\
\text { Gradiente de velocidade média de mistura } \\
\text { rápida - Gmr }\end{array}$ & $60 \mathrm{~s}$ \\
\hline $\begin{array}{c}\text { Tempo de floculação - Tf } \\
\text { Gradiente de velocidade média da } \\
\text { floculação - Gf }\end{array}$ & $20 \mathrm{~min}$ \\
\hline $\begin{array}{c}\text { Velocidade de sedimentação - Vs } \\
\text { Taxa de filtração - Tfil } \\
\text { Tempo de filtração }\end{array}$ & $20 \mathrm{~s}^{-1}$ \\
\hline
\end{tabular}


Após seleção das condições de coagulação, foram realizados ensaios de reprodução considerando as etapas de coagulação, floculação, sedimentação e filtração em areia, simulando, deste modo, o tratamento por ciclo completo, em escala de bancada. $O$ sistema de filtros de laboratório de areia (FLAs) foi constituído por filtros em acrílico transparente de $19 \mathrm{~mm}$ de diâmetro, 40 $\mathrm{cm}$ de altura e areia aderida na parede interna, de modo a evitar formação de correntes preferenciais durante a filtração. $A$ areia utilizada foi do tipo 2, com faixa granulométrica entre 0,42 e 0,84 mm e tamanho efetivo (D10) de $0,62 \mathrm{~mm}$ (KURODA, DE PAULA e DI BERNARDO, 2002).

Para avaliar a eficiência do tratamento por ciclo completo para águas contendo células de Microcistys sp. e MCs, foram coletadas amostras, após sedimentação e após filtração, para caracterização em relação aos parâmetros de desempenho: densidade celular, turbidez, clorofila-a e alumínio, segundo APHA, AWWA, WEF (2012) e MCs extracelulares e totais.

\subsection{Tratamento por ciclo completo associado à adsorção em CAP e em CAG}

Considerando os custos e as dificuldades para aquisição de CAPs e CAGs importados e as condições de aplicação em escala real, optou-se por utilizar apenas os carvões selecionados nacionais nos experimentos de tratabilidade.

Para avaliar a associação do tratamento por ciclo completo e adsorção em CAP para remoção de células de Microcystis sp. e de MCs, foram realizados experimentos em escala de bancada, em Jarteste, utilizando-se a AE2, os mesmos parâmetros operacionais descritos na Tabela 1 e as dosagens do CAP nacional selecionado, considerando:
- Tempo de contato de 60 minutos: simulando a adição de CAP na captação de água bruta, mantendo o carvão em contato com as MCs até o início da etapa de sedimentação. Assim, as suspensões de CAP foram adicionadas previamente aos jarros contendo a AE2 e mantidas sob agitação de $20 \mathrm{~s}^{-1}$ por 30 minutos, seguidas de ajuste do $\mathrm{pH}$ e das etapas do ciclo completo;

- Tempo de contato de 30 minutos: simulando a adição de CAP logo após a coagulação até período inicial da etapa de sedimentação. Assim, as suspensões de CAP foram adicionadas aos jarros, 1 min após o início da coagulação sem ajuste de $\mathrm{pH}$, seguidas das etapas do ciclo completo.

Em relação à adsorção em CAG nacional selecionado, o mesmo foi empregado associado ao ensaio de tratabilidade por ciclo completo, após a etapa de filtração em areia, seguindo as mesmas condições operacionais utilizadas no experimento de seleção de CAG, porém com duração de $72 \mathrm{~h}$. Os parâmetros de desempenho avaliados nos tratamentos associados foram os mesmos do tratamento por ciclo completo.

\section{RESULTADOS E DISCUSSÃO}

\subsection{Amostragem e caracterização preliminar de CAPs e CAPs}

As características dos carvões estudados são apresentadas na Tabela 3, na qual pode-se observar que, dentre os nacionais, todos foram ativados fisicamente e, com exceção do CAP 12, de origem animal, os demais foram de origem vegetal, provenientes do babaçu, pinus, madeira e coco. Já os CAPs importados foram de origem mineral com ativação química. 
Tabela 3 - Caracterização preliminar dos CAPs e CAGs amostrados em relação à origem, método de ativação, matéria-prima, Número de lodo - NI, Índice de Fenol - IF e Índice de Azul de Metileno - IAM

\begin{tabular}{|c|c|c|c|c|c|c|c|}
\hline Índice & Tipo & Origem & Ativação & Matéria-prima & $\begin{array}{c}\text { IF } \\
\left(\mathrm{g} \mathrm{L}^{-1}\right)\end{array}$ & $\begin{array}{c}\text { NI } \\
\left(\mathrm{mg} \mathrm{g}^{-1}\right)\end{array}$ & $\begin{array}{c}\text { IAM } \\
\left(\mathrm{mg} \mathrm{g}^{-1}\right)\end{array}$ \\
\hline 1 & CAP & Vegetal & Física & Babaçu & 2,1 & 853 & 75 \\
\hline 2 & CAP & Vegetal & Física & Babaçu & - & 934 & 88 \\
\hline 3 & CAP & Vegetal & Física & Pinus & 2,3 & 629 & 42 \\
\hline 4 & CAP & Vegetal & Física & Pinus & - & 862 & 108 \\
\hline 5 & CAP & Vegetal & Física & Pinus & 2,1 & 942 & 134 \\
\hline $6(*)$ & CAP & Mineral & Química & Mineral betuminoso & - & 966 & 142 \\
\hline $7(*)$ & CAP & Mineral & Química & Carvão Mineral & 2,1 & 1130 & 203 \\
\hline $8(*)$ & CAP & Mineral & Química & Carvão Mineral & 2,2 & 1098 & 199 \\
\hline 9 & CAP & Vegetal & Física & Madeira & - & 1019 & 171 \\
\hline 10 & CAP & Vegetal & Física & Madeira & - & 765 & 116 \\
\hline 11 & CAP & Vegetal & Física & Madeira & - & 621 & 98 \\
\hline 12 & CAP & Animal & Física & Osso & - & 4 & 16 \\
\hline 13 & CAP & Vegetal & Física & Madeira & - & 465 & 67 \\
\hline 14 & CAP & Vegetal & Física & Coco & 3,1 & 770 & 133 \\
\hline 15 & CAG & Vegetal & Física & Endocarpo coco & - & 936 & 54 \\
\hline 16 & CAG & Vegetal & Física & Endocarpo coco & - & 910 & 79 \\
\hline 17 & CAG & Animal & Física & Osso & - & 21 & 11 \\
\hline 18 & CAG & Vegetal & Física & Endocarpo coco & - & 850 & - \\
\hline 19 & CAG & Vegetal & Física & Endocarpo coco & - & 976 & 190 \\
\hline 20 & CAG & Vegetal & Física & Endocarpo coco & - & 845 & 81 \\
\hline $21(*)$ & CAG & Mineral & Química & Carvão Mineral & - & 1117 & 199 \\
\hline
\end{tabular}

(*) Carvões importados

Em relação aos índices apresentados, o NI está relacionado à microporosidade do carvão, uma vez que requer poros com abertura inferior a 1 nm. Já o IAM está relacionado à mesoporosidade do carvão, uma vez que requer poros com abertura próxima a $2 \mathrm{~nm}$ (WARHURST; MCCONNACHIE; POLLARD, 1997; EL-HENDAWY et al., 2001). Dessa forma, espera-se que, para águas contendo moléculas de MCs, os CAPs e CAGs que apresentam porosidade com maiores valores de IAM e, consequentemente, maior volume de mesoporos, sejam mais eficientes para remoção de MCs.

\subsection{Seleção de CAPs e CAGs e determinação das condições de maior eficiência de adsorção para o CAP selecionado}

Para selecionar o CAP de maior eficiência para adsorção de MCs, foi utilizada a AE1, com con- centração de MCs de 19,28 $\mu \mathrm{g} \mathrm{L}^{-1}$ (concentração prevista de $20 \mathrm{~g} \mathrm{~L}^{-1}$ ) e dosagem de CAP de 25 $\mathrm{mg} \mathrm{L}^{-1}$. Os resultados de concentração residual de MCs, para os 14 CAPs e 7 CAGs utilizados são apresentados na Fig. 1.

De acordo com os resultados obtidos, a menor concentração de MCs residuais observadas para os CAPs nacionais ocorreu para o CAP5, que resultou em concentração residual de $1,48 \mu \mathrm{g} \mathrm{L}^{-1}$ e remoção de $92,3 \%$. Dentre os CAs importados, o CAP7(") e o CAP8(") apresentaram as menores concentrações residuais de MCs, sendo elas, 0,31 e $0,30 \mu \mathrm{g} \mathrm{L}^{-1}$, respectivamente, com remoção de $98,4 \%$. Embora, dentre os carvões nacionais, o CAP5 tenha sido o selecionado, a concentração residual de MCs não atendeu ao limite estabelecido pelo Anexo XX da Portaria de Consolidação $n^{\circ} 5 / 2017$, e o valor foi bem superior aos residuais observados para os CAP7(*) e CAP8(*). 
Figura 1 - Concentração residual de MCs e remoção para os CAPs e CAGs amostrados

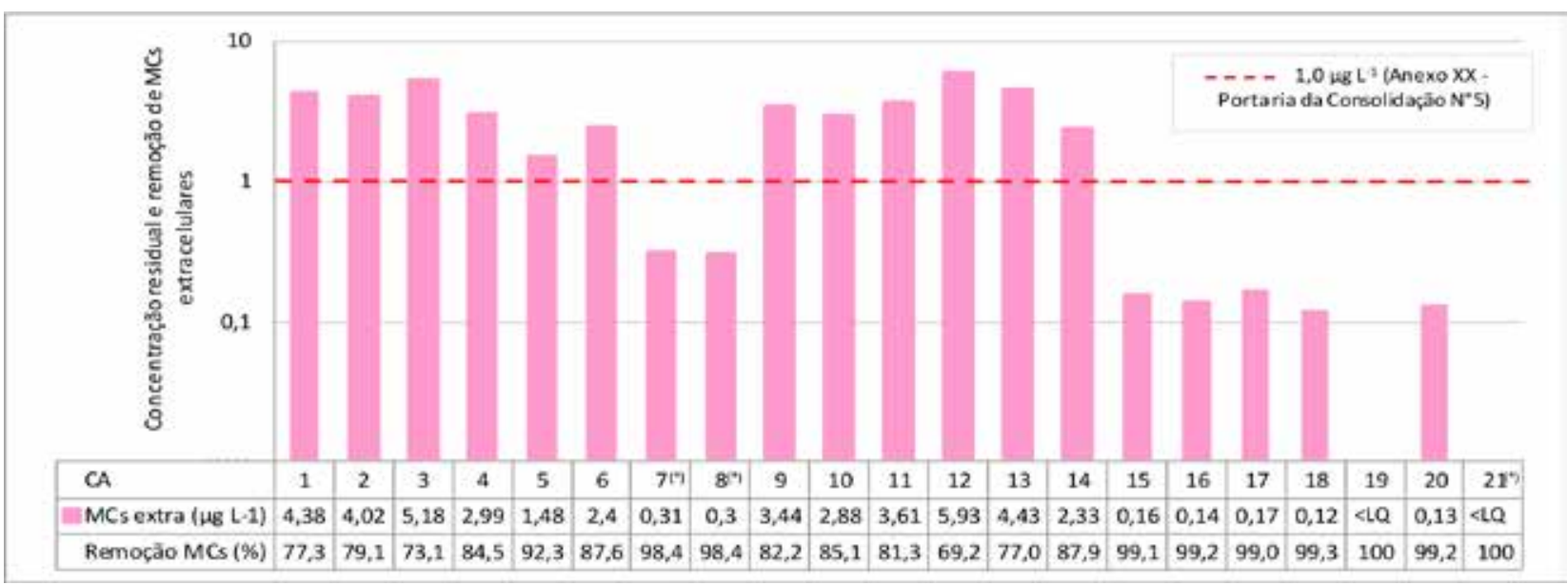

(*) CAPs e CAGs importados

Em relação aos CAGs amostrados, podem-se observar elevados valores de remoção para todos dos carvões, com porcentagens acima de 99\%. Os CAGs com melhor desempenho foram os CAGs 19 (nacional) e 21(*) (importado), com concentrações residuais de MCs abaixo do LQ.

Segundo Albuquerque Júnior (2006), que avaliou a caracterização e a ativação de carvões ativados de origem mineral e vegetal, os carvões de origem mineral possuem estrutura porosa mais favorável à adsorção de MCs em relação ao carvão vegetal, justificando as elevadas remoções dos CAPs $7\left(^{*}\right)$ e $8(*)$, de origem mineral em relação ao CAP5, de origem vegetal. Entretanto, Donati et al. (1994), e Mohamed et al. (1998) observaram que carvões provenientes da madeira apresentaram maior capacidade adsortiva em relação às moléculas de MCs.

Por outro lado, de forma geral, os carvões que apresentaram maior eficiência na adsorção de MCs corresponderam àqueles que resultaram em maiores valores de IAM e, consequentemente, de mesoporosidade, conforme constatação obtida por Donati et al., (1994), Mohamed et al., (1998), Kuroda et al., (2005), Zhang e Jiang, (2011), Teng et al., (2013) e Huang et al. (2015), ressaltando a importância desse parâmetro na predição da efi- ciência adsortiva para moléculas de maior massa molecular como as MCs.

Após seleção do CAP5, foi realizado o experimento para determinar as condições mais adequadas de adsorção, utilizando-se a AE2, com concentração de MCs extracelulares de $18,95 \mu \mathrm{g}$ $\mathrm{L}^{-1}$ (concentração prevista de $20 \mu \mathrm{g} \mathrm{L}^{-1}$ ) e densi-

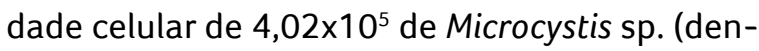
sidade prevista de $10^{5}$ cel $\mathrm{mL}^{-1}$ de M. sp.). A concentração de MCs totais (intra e extracelulares) da $A E 2$ resultou em $30,75 \mu \mathrm{g} \mathrm{L}^{-1}$.

Na Fig. 2 são apresentados os resultados obtidos, podendo-se observar que as dosagens de 5, 10 e $25 \mathrm{mg} \mathrm{L}^{-1}$ de CAP5 não foram suficientes para reduzir a concentração de MCs a valores inferiores a $1,0 \mu \mathrm{g} \mathrm{L}^{-1}$, de acordo com o Anexo XX - Portaria da Consolidação ${ }^{\circ} 5$, mesmo para o tempo de contato de 120 minutos. Para as dosagens de CAP5 de 40 e $50 \mathrm{mg} \mathrm{L}^{-1}$, foram observadas concentrações residuais inferiores ao valor estabelecido pela legislação, com residuais de MCs de 0,90 e $0,81 \mu \mathrm{g} \mathrm{L}^{-1}$ para os tempos de contato de 60 e 30 minutos, respectivamente, dispensando, assim, a necessidade do emprego do tempo de contato superior de 120 min para atender ao valor limite definido pela legislação. 
Figura 2 - Concentração residual de MCs para diferentes tempos de contato e dosagens de CAP5 utilizando-se AE2 ( $\mathrm{pH}=7,0$; agitação= $150 \mathrm{rpm}$; temperatura $=25 \pm 1^{\circ} \mathrm{C}$ )

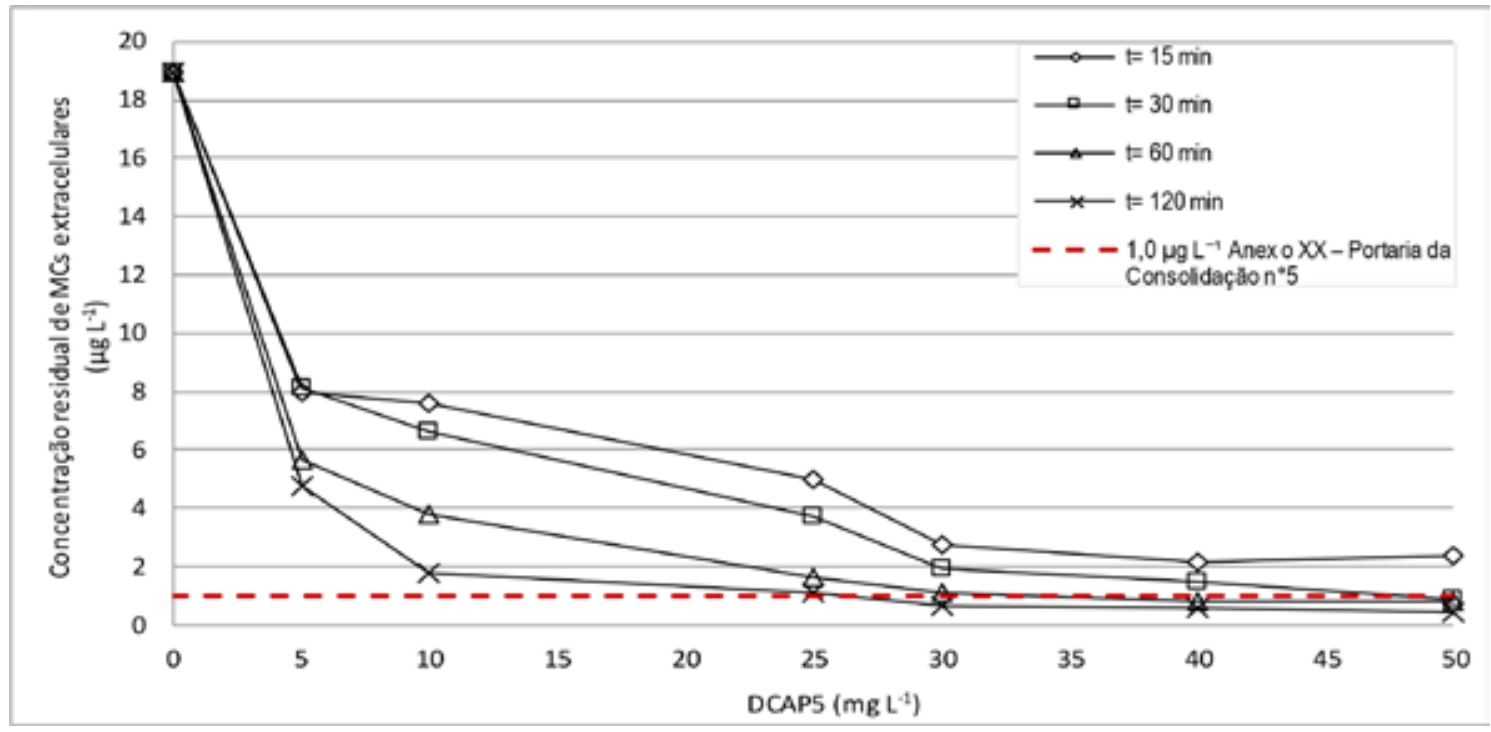

Dessa forma, considerando uma situação real de manancial eutrofizado com águas contendo MCs e células de Microcystis sp., as condições de adsorção com o CAP5, que produziram efluente com qualidade compatível ao Anexo XX - Portaria da Consolidação ${ }^{\circ} 5$ foram: dosagens de CAP5 de 40 e $50 \mathrm{mg} \mathrm{L}^{-1}$ para os tempos de contato de 60 e 30 minutos, respectivamente. Tais resultados evidenciaram que o acréscimo de $25 \%$ na dosagem do CAP5 e a redução de $100 \%$ do tempo de contato foram suficientes para a obtenção de eficiências similares de remoção e atendimento à legislação vigente em relação às MCs.

Os resultados do experimento de reprodução em reatores estáticos/equipamento Jarteste com volume reacional de $2 \mathrm{~L}$ confirmaram as mesmas condições de adsorção obtidas no experimento com volume reacional de $50 \mathrm{~mL}$, indicando que não houve influência do efeito de escala nos resultados experimentais, uma vez que ocorreram remoções celular, de turbidez, e de MCs da mesma ordem de grandeza para ambas as escalas.

\subsection{Ciclo completo com filtração em areia}

Para simulação do tratamento por ciclo completo foi utilizada a AE2 e, inicialmente, foi determinada a condição mais adequada de coagulação, considerando a qualidade do sobrenadante e valores de $\mathrm{pH}$ e dosagens de alumínio pré-estabelecidos. Os resultados obtidos são apresentados na Fig. 3.

De forma geral, comparando-se os valores residuais de densidade celular e de turbidez, pôde-se observar que as maiores remoções ocorreram para o $\mathrm{pH}$ de 6,7, independentemente da dosagem de alumínio aplicada, corroborando os resultados obtidos por Fonseca (2014), que utilizou AE com características similares. Para esse valor de $\mathrm{pH}$, as dosagens de alumínio de 4,0 e 6,0 $\mathrm{mg} \mathrm{L}^{-1}$ apresentaram as maiores eficiências de remoção desses parâmetros, com diferença de apenas $2 \%$, o que não justifica a adoção da maior dosagem. Assim, selecionou-se como condição de coagulação: dosagem de $4,0 \mathrm{mg} \mathrm{L}^{-1}$ de alumínio e $\mathrm{pH}$ de 6,7. 
Para a seleção da dosagem do PAC, considerouse também a concentração residual de alumínio na água após tratamento, uma vez que, de acordo com o Anexo XX da Portaria de Consolidação $n^{\circ} 5 / 2017$, o limite máximo permitido de alumínio é de 0,2 $\mathrm{mg} \mathrm{L}^{-1}$ (BRASIL, 2017). É importante monitorar esse parâmetro, uma vez que o alumínio é um composto neurotóxico associado a encefalopatias graves, podendo causar prejuízos à saúde.

Chow et al. (1999) investigaram as condições de maior eficiência de coagulação, em escala de bancada, utilizando o sulfato de alumínio, para águas naturais do reservatório South Para, na Austrália, contendo $4,5 \times 10^{5} \mathrm{cel} \mathrm{mL}^{-1}$ de Microcystis aeruginosa. Após a realização de ensaios de coagulação, obteve como melhor resultado: dosagem de alumínio de 4,8 $\mathrm{mg} \mathrm{L}^{-1}$ e pH de 6,7; condições muito próximas às obtidas neste trabalho.

Sun et al. (2012) avaliaram as condições de coagulação, em escala de bancada, que acarretariam menor lise celular, evitando a liberação de cianotoxinas dissolvidas. Para tanto, foram adicionadas culturas de Microcystis aeruginosa com densidade celular da ordem de $2 \times 10^{6} \mathrm{cel} \mathrm{mL}^{-1}$ às águas naturais do reservatório Queshan, na China. Após comparar diferentes dosagens de alumínio, agitação rápida e lenta, obteve como melhor condição de coagulação a dosagem de $4,7 \mathrm{mg} \mathrm{L}^{-1}$ de Al, mistura rápida de $250 \mathrm{rpm}$ com tempo de $1 \mathrm{~min}$ e mistura lenta de $20 \mathrm{rpm}$ com tempo de $20 \mathrm{~min}$. Apesar de não relatar o pH utilizado no trabalho, as demais condições se aproximaram das utilizadas neste trabalho.
Após determinação das condições de coagulação, foi realizado o experimento de reprodução do tratamento por ciclo completo, incluindo a filtração em areia, para a condição de coagulação selecionada, cujos resultados estão apresentados na Fig. 4. Para avaliar a eficiência desse tratamento, foram caracterizadas as amostras do sobrenadante (DEC) e do filtrado em filtro de areia de laboratório (FLA), de acordo com os parâmetros descritos na Tabela 2.

$\mathrm{Na}$ etapa de sedimentação, verificaram-se porcentagens de remoção celular de $97,5 \%$ e densidade residual de $1,01 \times 10^{4}$ cel $\mathrm{mL}^{-1}$. Após filtração, a remoção celular foi aumentada para $99,9 \%$, e a densidade residual de Microcystis sp. foi de $578 \mathrm{cel} \mathrm{mL}^{-1}$. Tais valores evidenciam a elevada eficiência da filtração para retenção de células intactas e, consequentemente, de MCs intracelulares (CHORUS; BARTRAM, 1999; DRIKAS et al., 2001; ALBUQUERQUE JR, 2006; TEIXEIRA; ROSA, 2007; KURODA et al., 2006; DI BERNARDO et al., 2006, LIBÂNIO, 2010), especialmente quando aplicada sob condições experimentais controladas.

Em relação às MCs totais e extracelulares, observaram-se, após a etapa da sedimentação, concentrações residuais de 25,59 e $18,34 \mu \mathrm{g} \mathrm{L}^{-1}$ com remoções de 16,8 e 3,2\%, respectivamente. Após filtração, os residuais de MCs totais e extracelulares foram de 22,67 e 17,24 $\mathrm{g} \mathrm{L} \mathrm{L}^{-1}$, que corresponderam às remoções de 26,3 e 9,0\%, respectivamente. As concentrações residuais de MCs totais e extracelulares observadas ao final do tratamento por ciclo completo evidenciaram a limitada eficiência dessa técnica para remoção de MCs dissolvidas. 
Figura 3 - Valor de turbidez e densidade de M. sp da AE2 e da amostra decantada para diferentes condições de coagulação ( $\mathrm{Tmr}=1 \mathrm{~min}, \mathrm{Gmr}=600 \mathrm{~s}^{-1}, \mathrm{Tf}=20 \mathrm{~min}, \mathrm{GF}=20 \mathrm{~s}^{-1}, \mathrm{Vs}=1,0 \mathrm{~cm} \mathrm{~min}^{-1}$ )

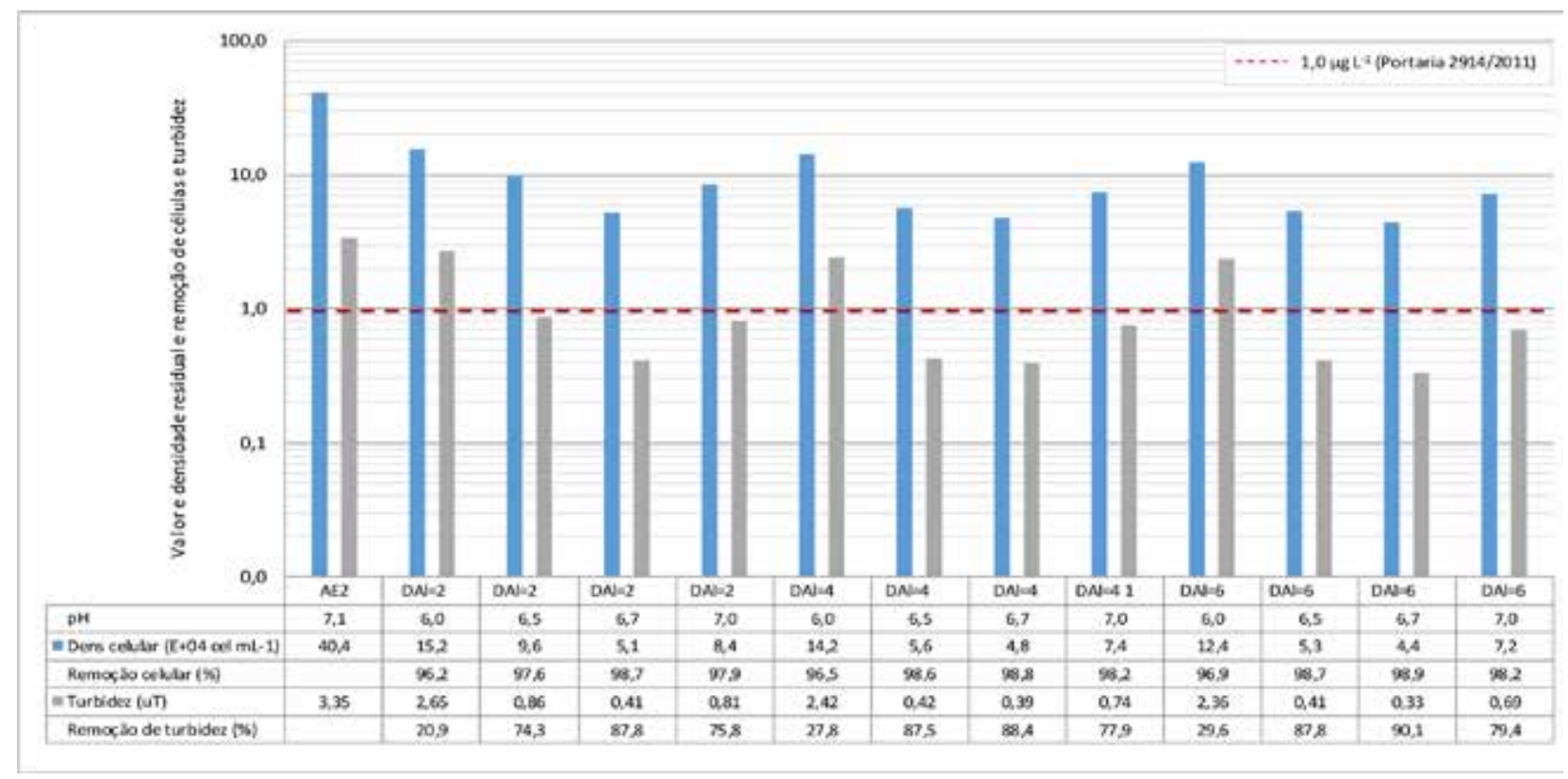

AE2: água de estudo 2; DAl (mg L-1): dosagem de alumínio

Guerra (2015) realizou o tratamento por ciclo completo para água de estudo contendo $22,4 \mu \mathrm{g}$ $\mathrm{L}^{-1}$ de MCs e verificou, após a filtração em areia, concentrações residuais de $18,0 \mu \mathrm{g} \mathrm{L}^{-1}$ de MCs, apresentando remoções da ordem de $18 \%$. Morais (2012) obteve resultados similares, apesar da baixa concentração de MCs na água de estudo $\left(3,27 \mu \mathrm{g} \mathrm{L}^{-1}\right)$. Após filtração, obteve valores residuais de $2,43 \mu \mathrm{g} \mathrm{L}^{-1}$ com remoção de $25,7 \%$, o que comprova que mesmo com baixas concentrações de MCs, o ciclo completo não é capaz de produzir água com qualidade compatível ao Anexo XX da Portaria de Consolidação n 5/2017. Tais valores corroboram os resultados obtidos, enfatizando a necessidade de adoção de tratamento complementar, eficiente na remoção de toxinas dissolvidas, como descrito por Himberg et al. (1989); Lambert et al. (1996), Chow et al. (1999), Drikas et al. (2001), Newcombe e Nichol- son (2004), De Júlio (2009), Dixon et al. (2011) e Park et al., (2017), entre outros autores.

Em relação à clorofila-a e turbidez, verificou-se que houve elevada redução desses parâmetros no tratamento por ciclo completo. Na sedimentação, observaram-se remoções de 90,3\% e 91,5\% (com concentrações residuais de 3,3 $\mu \mathrm{g}$ $\mathrm{L}^{-1}$ e 0,35 uT, respectivamente). Após filtração, essas remoções foram maiores, apresentando reduções de 97,2\%, e 95,7\% (com concentrações remanescentes de $0,95 \mu \mathrm{g} \mathrm{L}^{-1}$ e $0,18 \mathrm{uT}$, respectivamente). Nesse caso, esses parâmetros estão diretamente relacionados à presença de material celular; portanto, de acordo com os resultados obtidos, acompanharam a redução da densidade celular de Microcystis sp., demonstrando a eficiência do tratamento por ciclo completo para esses parâmetros. 
Considerando os resultados obtidos para o tratamento por ciclo completo, pode-se observar que essa técnica mostrou-se eficiente para remoção de células de Microcystis sp e, consequentemente, de MCs intracelulares, entretanto pouco efetiva para remoção de MCs extracelulares. Sendo assim, para atender ao Anexo XX da Portaria de Consolidação $n^{\circ}$ 5/2017 e garantir a qualidade de água, o tratamento por ciclo completo requer associação às técnicas complementares que garantam a remoção de MCs extracelulares.

\subsection{Ciclo completo associado à adsorção em CAP e CAG}

Para avaliar a eficiência do tratamento por ciclo completo associado à adsorção em CAP, foram consideradas as condições de adsorção: dosagem de $50 \mathrm{mg} \mathrm{L}^{-1}$ de CAP5, para o tempo de contato de $30 \mathrm{~min}$, e de $40 \mathrm{mg} \mathrm{L}^{-1}$ de CAP5, para o tempo de contato de $60 \mathrm{~min}$, conforme delineamento experimental e caracterizadas as amostras do sobrenadante - CAP-DEC e do filtrado em areia - CAP-FLA, segundo os parâmetros de desempenho pré-definidos (Fig. 4).

De acordo com os resultados obtidos no tratamento por ciclo completo e filtração em areia sem adsorção em CAP, verificou-se que os parâmetros de turbidez, densidade celular, alumínio residual e clorofila-a não apresentaram diferenças relevantes de remoção, para as diferentes condições adsortivas experimentais de aplicação.

A avaliação da eficiência de remoção de MCs foi realizada apenas para as MCs extracelulares, uma vez que não foi possível separar as células de Microcystis sp. das partículas de CAP. Dessa forma, foi avaliada a remoção de MCs extracelulares e observado, para dosagem de CAP de $50 \mathrm{mg} \mathrm{L}^{-1}$ e tempo de contato de $30 \mathrm{~min}$, na etapa de sedimentação e filtração, remoções de 97,9 e $99,1 \%$ e valores residuais de 0,41 e $0,18 \mathrm{mg} \mathrm{L}^{-1}$, respectivamente. Para a dosagem de CAP de $40 \mathrm{mg} \mathrm{L}^{-1}$ e tempo de contato de 60 min, obteve-se maior desempenho na etapa de sedimentação e filtração, com remoções de 98,9 e $99,5 \%$ e concentrações residuais de $0,22 \mu \mathrm{g} \mathrm{L}^{-1}$ e $0,10 \mu \mathrm{g} \mathrm{L}^{-1}$, respectivamente.

Apesar de o Anexo XX da Portaria de Consolidação $n^{\circ}$ 5/2017 ter sido atendido em relação às MCs para as duas condições adsortivas experimentais de aplicação, a condição que empregou o maior tempo de contato e a menor dosagem de CAP (60 min e $40 \mathrm{mg} \mathrm{L}^{-1}$ ), apresentou maiores percentuais de remoção após as etapas de sedimentação e filtração, indicando que o maior tempo de contato possibilitado pela aplicação do CAP na captação de água bruta pode ser uma alternativa técnica promissora para esta aplicação. 
Figura 4 - Valor e concentração residuais de densidade celular, MCs extracelulares, turbidez, clorofila-a e alumínio residual da AE2 antes e após tratamentos

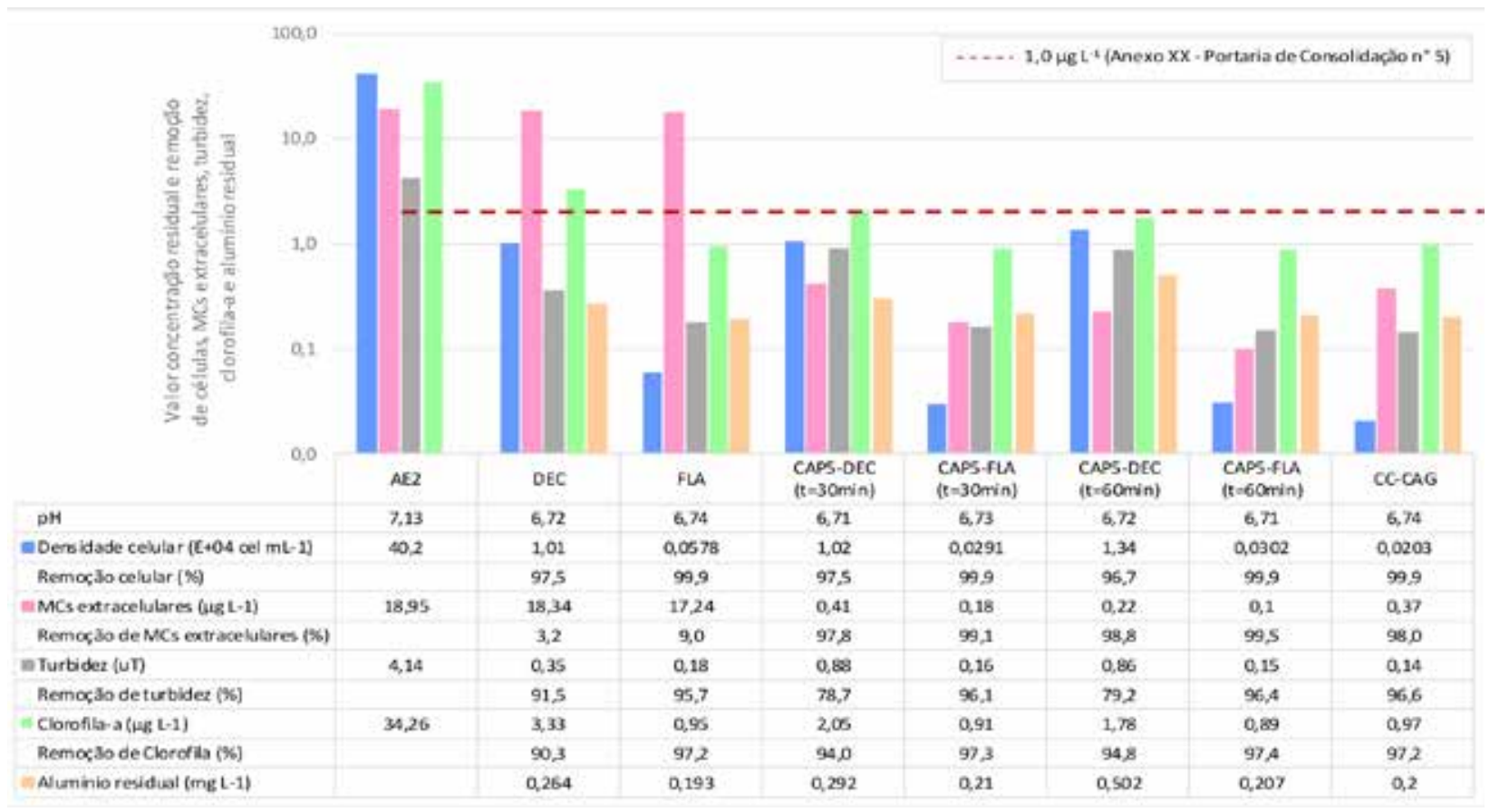

AE2: água de estudo 2; DEC: amostra decantada; FLA: amostra filtrada; CAP-DEC: amostra decantada após adsorção em CAP; CAP-FLA: amostra filtrada após adsorção em CAP; CC-CAG: amostra de ciclo completo após adsorção em CAG, com tempo de experimento de $72 \mathrm{~h}$

Ho et al. (2011) avaliaram a remoção de MCs utilizando adsorção em CAP, com dosagens de 5, $10,25,50$ e $100 \mathrm{mg} \mathrm{L}^{-1}$, para amostras contendo $22 \mu \mathrm{g} \mathrm{L}^{-1}$ de MCs, e observaram elevadas remoções com concentração residual inferior a $1,0 \mu \mathrm{g}$ $\mathrm{L}^{-1}$ de $M C s$, para dosagens iguais ou superiores a $50 \mathrm{mg} \mathrm{L}^{-1}$ de CAP, com tempo de contato de 30 minutos, como observado no presente estudo. Müller (2009) avaliou a eficiência da adsorção em CAP, proveniente de madeira, aplicado 5 minutos antes da coagulação, para uma água de estudo contendo $10 \mathrm{\mu g} \mathrm{L}^{-1}$ de MCs e dosagens de $20 \mathrm{e}$ $85 \mathrm{mg} \mathrm{L}^{-1} \mathrm{mg} \mathrm{L}^{-1}$ de CAP, e obteve como resultado valores residuais de 1,2 e 0,2 $\mathrm{\mu g} \mathrm{L}^{-1}$ de MCs, para as respectivas dosagens de CAP.

De modo geral, corroborando dados da literatura, constatou-se pelos resultados experimentais a necessidade de empregar dosagens de $40 \mathrm{mg} \mathrm{L}^{-1}$ ou superiores, a depender do ponto de aplicação e das características do CAP, para atender ao limite máximo de 1,0 $\mathrm{\mu g} \mathrm{L}^{-1}$ de MCs para o tratamento de águas contendo MCs dissolvidas da ordem de $20 \mu \mathrm{g} \mathrm{L}^{-1}$. Entretanto, é imprescindível a realização de investigações preliminares para selecionar o CAP, bem como a dosagem necessária para cada caso.

Para avaliar a capacidade adsortiva do CAG nacional selecionado em relação à remoção de MCs, foram realizados experimentos de reprodução do tratamento por ciclo completo, utilizando os parâmetros operacionais descritos na Tabela 1. Assim, as amostras obtidas após a filtração em areia, com concentração de MCs extracelulares de $17,24 \mu \mathrm{g} \mathrm{L}^{-1}$, foram encaminhadas para o filtro de CAG19. Os resultados desse experimento também estão apresentados na Fig. 4.

Os resultados obtidos com o emprego do CAG19 apresentaram valores acima do limite de detecção de $0,12 \mu \mathrm{g} \mathrm{L}^{-1}$ somente após 30 horas de 
experimento, não sendo observadas concentrações residuais de MCs maiores que o valor máximo permitido pelo Anexo XX da Portaria de Consolidação $n^{\circ} 5 / 2017$, mesmo após as 72 horas de experimento, com concentração residual máxima de 0,37 $\mu \mathrm{g} \mathrm{L}^{-1}$ (valor utilizado na Fig. 4).

O estudo de Oliveira e Azevedo (2004), utilizando AE com concentrações de MCs de 10,0 $\mu \mathrm{g} \mathrm{L-1}$, avaliou a capacidade adsortiva para três CAGs: CAG1 de origem vegetal, predominantemente microporoso e tempo de contato de 0,15 min, o CAG2 e o CAG3 com predominância de mesoporos e de origem mineral e animal e tempo de contato de 0,15 e 0,29 min, respectivamente. Considerando a concentração residual de MCs, observou-se que o CAG3 apresentou melhor desempenho, removendo $97,8 \%$ das MCs, seguido pelo CAG2, com percentual de remoção de $80 \%$ e o CAG1, com remoção da ordem de $65 \%$. Tais resultados demonstram a importância de utilizar CAGs mesoporosos para a adsorção de MCs.

Guerra et al (2015) realizaram o tratamento de águas contendo células de cianobactérias e MCs por ciclo completo associado à filtração/adsorção para os CAGs 1 e 2, com tempo de contato teórico de 45 segundos, utilizando efluente obtido após filtração em areia, com concentração de MCs de 18,0 $\mu \mathrm{g} \mathrm{L}^{-1}$. Como resultado, observaram para o CAG1 e CAG2 valores residuais de MCs inferiores a $1,0 \mu \mathrm{g} \mathrm{L}^{-1}$, até 8 e $2 \mathrm{~h}$ de funcionamento dos filtros, respectivamente.

De modo geral, pode-se concluir que o tratamento por ciclo completo, associado à adsorção em CAP e CAG, foi capaz de reduzir as concentrações de MCs aos níveis exigidos pelo Anexo XX da Portaria de Consolidação $n^{\circ} 5 / 2017$, demonstrando ser uma alternativa técnica eficiente para o tratamento de água contendo células de Microcystis sp e MCs.

\section{CONCLUSÃO}

O Índice de Azul de Metileno (IAM), utilizado para caracterização dos carvões, mostrou ser um parâmetro preditivo da capacidade adsortiva para MCs importante a ser considerado na seleção de CAPs e CAGs, uma vez que os carvões com elevados valores de IAM apresentaram as maiores eficiências de adsorção de MCs.

Para águas contendo células de Microcystis $\mathrm{sp}$ com densidade da ordem de $105 \mathrm{cel} \mathrm{mL}^{-1}$ e concentração de microcistinas (MCs) com $20 \mu \mathrm{g} \mathrm{L}^{-1}$, submetidas ao tratamento por ciclo completo com e sem adsorção em carvão ativado pulverizado (CAP) e granular (CAG), pode-se comprovar que o tratamento por ciclo completo composto por coagulação, floculação, sedimentação e filtração em areia mostrou-se eficiente na remoção de células de Microcystis sp. e MCs intracelulares, porém ineficiente em relação à remoção MCs extracelulares, tendo apresentado remoção de 9,0\% com concentração residual de 17,24 de MCs.

$O$ tratamento de ciclo completo associado à adsorção em CAP foi eficiente para remoção de MCs extracelulares, considerando sua aplicação tanto na captação de água bruta com tempo de contato prévio de $30 \mathrm{~min}$ (totalizando $60 \mathrm{~min}$ de contato) como no final da mistura rápida com tempo de contato de $30 \mathrm{~min}$.

O tratamento por ciclo completo seguido de adsorção em filtro de CAG apresentou elevada eficiência para a remoção de MCs extracelulares.

\section{AGRADECIMENTOS}

Universidade Estadual de Londrina; Conselho Nacional de Desenvolvimento; Científico e Tecnológico (CNPq); Coordenação de Aperfeiçoamento de Pessoal de Nível Superior (Capes); Fundação Araucária. 


\section{CONTRIBUIÇÃO DOS AUTORES}

Todos os autores contribuíram de forma igualitária.

\section{REFERÊNCIAS}

ALBUQUERQUE JUNIOR, E. C. Produção e caracterização de carvão ativado para remoção de microcistinas. 2006. 239f. Tese (Doutorado em Engenharia Química) - Universidade Estadual de Campinas, Unicamp, 2006.

AMERICAN SOCIETY FOR TESTING AND MATERIALS. Standard practice for determination of adsorptive capacity of activated carbon by aqueous phase isotherm technique - D3860-1998. In: AMERICAN SOCIETY FOR TESTING AND MATERIALS. Standards on activated carbon. Philadelphia, p. 47-49, 2000.

ASSOCIAÇÃO BRASILEIRA DE NORMAS TÉCNICAS - ABNT. Carvão ativado pulverizado - Determinação do número de iodo - Método de ensaio - especificações: MB - 3410. Rio de Janeiro, 1991.

Carvão ativado pulverizado - Determinação do índice de fenol - Método de ensaio - especificações: $M B$ - 3411. Rio de Janeiro, 1991.

Carvão ativado pulverizado - Especificação: ABNT NBR 11834:1991. Rio de Janeiro, 1991.

APHA, AWWA, WEF. Standard Methods for the Examination of Water and Wastewater. American Public Health Association (APHA), American Water Works Association (AWWA) e Water Environment Federation (WEF). 22 ed. Washington: APHA, 2012.

BETTINA, C.H.; STEFAN, J.H.; DANIEL, R.D. Cyanobacterial toxins: removal during drinking water treatment, and human risk assessment. Environmental. Toxicol, v. 108, p. 113 -122, 2015.

BRASIL. Ministério da Saúde. Portaria de Consolidação n. ${ }^{\circ}$ 5, 28 de Setembro de 2017. Dispõe sobre os procedimentos de controle e de vigilância da qualidade de água para consumo humano e seu padrão de potabilidade. Diário Oficial da União República Federativa do Brasil, Brasília, DF, 2017

CHATZIEFTHIMIOU, A. D. et al. Cyanobacteria and cyanotoxins are present in drinking water impoundments and groundwater wells in desert environments. Toxicon, v. 114, n. 10, p. 75-84, 2016.

CHORUS, I., BARTRAM, J. Toxic cyanobacteria in water: a guide to their public health consequences, monitoring and management. World Health Organization (WHO). Londres: Ed E\&FN Spon, 1999.

CHOW, C. W. K., HOUSE, J., VELZEBOER, R. M. A., DRIKAS, M., BUR$\mathrm{CH}, \mathrm{M}$. D., STEFFENSEN, D. A. The impact of conventional water treatment processes on cells of Cyanobacterium Microcystis aeruginosal. Water Research, v. 33, n. 15, p. 3253-3262, 1999.

COUTINHO, A.R.; BARBIERI, F.C.; PAVANI, P.A. Preparação de carvões ativados a partir de fibras de celulose. In: $2^{\circ}$ Encontro bra- sileiro de adsorção. Florianópolis, Santa Catarina, p. 139-144, 2000. Anais..

DELGADO, L. F.; CHARLES, P.; GLUCINA, K.; MORLAY, C. The removal of endocrine disrupting compounds, pharmaceutically activated compounds and cyanobacterial toxins during drinking water preparation using activated carbon-A review. Science of the Total Environment., v. 435 - 436, p. 509 - 525, 2012.

DE JÚLIO, M.; FIORAVANTE, D. A.; SELHORST FILHO, O.; DE JÚLIO, T. S.; OROSKI, F. I. Avaliação da remoção de cianobactérias e saxitoxinas da água bruta afluente à ETA Pitangui de Ponta Grossa/PR, utilizando os diagramas de coagulação para o cloreto férrico e o reagente de Fenton. Holos Environment, v. 9, n. 2, 2009.

DI BERNARDO, L.; DANTAS, A. B.; VOLTAN, P. E. N. Métodos e técnicas de tratamento de água. 3 ed, São Carlos: Editora LDiBe, 2017.

DI BERNARDO, L.; LUCA, S. J.; KURODA, E. K.; PEGORER, M. G. L. . Oxidação In: PÁDUA, V. L. (coord.). Contribuição ao estudo da remoção de cianobactérias e microcontaminantes orgânicos por meio de técnicas de tratamento de água para consumo humano. Programa de Pesquisa em Saneamento Básico - PROSAB. Belo Horizonte: SERMOGRAF. 504p, 2006.

DIXON, M. B.; RICHARD, Y.; HO, L.; CHOW, C. W. K.; O'NEILL, B. K.; NEWCOMBE, G. A. Coagulation-powdered activated carbon-ultrafiltration-multiple barrier approach for removing toxins from two Australian cyanobacterial blooms. Journal of Hazardous Materials, v. 186, n 2, p, 1553 - 1559, 2011.

DONATI, C.; DRIKAS, M.; HAYES, R. E NEWCOMBE, G. Water Research, v. 28, n. 8, p. 1735-1742, 2012.

DRIKAS, M.; CHOW, C. W. K.; HOUSE, J.; BURCH, M. D. Using coagulation, flocculation and settling to remove toxic cyanobacteria. Journal American Water Works Association - AWWA, v. 93. n. 2, p. $100-111,2001$.

EL-HENDAWY, A. N. A.; SAMRA, S. E.; GIRGIS, B. S. Adsorption characteristics of activated carbons obtained from corncobs. Colloids and surfaces $A$ : physicochemical and engineergins aspects, vol. 180, n. 3, p.209-221, 2001

FONSECA, G. L. Avaliação da remoção de cianobactérias e cianotoxinas pela técnica de tratamento de ciclo completo em escala de bancada. 81 f. Dissertação (Mestrado em Engenharia de Edificações e Saneamento) - Universidade Estadual de Londrina, 2014

FUNASA - Fundação Nacional de Saúde. Cianobactérias tóxicas na água para consumo humano na saúde pública e processos de remoção em água para consumo humano. Brasília: Ministério da Saúde: Fundação Nacional de Saúde, 2003.

GORHAM, P. R.; Toxic Algae. In: JACKSON (ed.) - Algae and Man. D. F. New York: Plenum Press, p. 307-36, 2012.

GUERRA, A. B et al. Remoção de microcistina-LR de águas eutrofizadas por clarificação e filtração seguidas de adsorção em carvão 
ativado granular. Engenharia Sanitária e Ambiental, v. 20, n. 4, p. $603-612,2015$.

HARKE, M. J. et al. A review of the global ecology, genomics, and biogeography of the toxic cyanobacterium, Microcystis spp. Harmful Algae, v. 54, p. 4-20, 2016.

HIMBERG, K.; KEIJOLA, A.M.; HIISVIRTA, L.; PYYSALO, H.; SIVONEN, $K$. The effect of water treatment processes on the removal of hepatotoxins from Microcystis and Oscillatoria cyanobacteria: a laboratory study. Water Research, v. 23, p. 979-984, 1989.

HO, L.; LAMBLING, P.; BUSTAMANTE, H.; DUKER, P.; NEWCOMBE, G. Application of powdered activated carbon for the adsorption of cylindrospermopsin and microcystin toxins from drinking water supplies. Water Research, v. 45, n. 9, p. 2954 - 2964, 2011.

HUANG, C., et al. Protonated mesoporous graphitic carbon nitride for rapid and highly efficient removal of microcystins. RSC. Adv., v. 56, n.5, p. 45368-45375, 2015.

JAPANESE INDUSTRIAL STANDARD - JIS K 1474. Test Methods for activated carbon. Japanese Standards Association, Tokyo, 2014.

KAWAHIGASHI, F; MENDES, M. B.; ASSUNÇÃO JR, V, G.; GOMES, V. H.; FERNANDES, F.; HIROOKA, E. Y.; KURODA, E. E. Pós-tratamento de lixiviado de aterro sanitário com carvão ativado. Engenharia Sanitária e Ambiental, v. 19, n.3, p. 235 - 244, 2012.

KURIAMA, F. Avaliação do potencial de biodegradação de microcistinas e biocontrole de cianobactérias por microrganismos em águas. 97 f. Dissertação (Mestrado em Engenharia de Edificações e Saneamento) - Universidade Estadual de Londrina, 2012.

KURODA, E. K.; DI BERNARDO, L. Determinação das condições de coagulação química para filtração direta com águas contendo células e subprodutos de cianobactérias. In: $23^{\circ}$ Congresso Brasileiro de Engenharia Sanitária e Ambiental, Campo Grande: Associação Brasileira de Engenharia Sanitária e Ambiental - ABES, 2006. Anais...

KURODA, E. K.; JÚNIOR, E. C. A.; DI BERNARDO, L.; TROFINO, J. C. Caracterização e escolha do tipo de carvão ativado a ser empregado no tratamento de águas contendo microcistinas. In: $23^{\circ}$ Congresso Brasileiro de Engenharia Sanitária e Ambiental, Campo Grande: Associação Brasileira de Engenharia Sanitária e Ambiental-ABES, 2005. Anais...

KURODA, E. K.; DI PAULA, D.; DI BERNARDO, L. Uso de filtros de laboratório de areia para determinação das condições de coagulação na filtração direta ascendente. In: VI Simpósio ítalo Brasileiro de Engenharia Sanitária e Ambiental, Vitória: Associação Brasileira de Engenharia Sanitária e Ambiental - ABES, 2002. Anais...

LAMBERT, T.W.; HOLMES, C.F.B.; HRUDEY, S.E. Adsorption of microcystin-LR by activated carbon and removal in full scale water treatment. Water Research, v. 30, n. 6, p. 1411-1422, 1996.
$\mathrm{LI}, \mathrm{X}$. et al. The fate of Microcystis aeruginosa cells during the ferric chloride coagulation and flocs storage processes. Environ. Technol., v. 36, n. 7, p. 920-928, 2015.

LIBÂNIO, M. Fundamentos de qualidade e tratamento de água, Ed. 3, Campinas -SP, Editora Átomo, 2010.

MOHAMED, Z. A.; CARMICHAEL, W. W.; AN, J.; EL-SHAROUNY, $H$. M. Activated carbon removal efficiency of microcystins in aqueous cell extract of Microcystis aeruginosa and oscillatoria tenuis strains isolated from egiptian freshwaters. England: John Wiley \& Sons, p. 197, 1998.

MOHAMED, Z. A.; MOHAMED, A. D., MOHAMED, I. A., AHMAD, K. E., WESAM, M. E. Occurrence of cyanobacteria and microcystin toxins in raw and treated waters of the Nile River, Egypt: implication for water treatment and human health. Environmental Science and Pollution Research, v. 22, n. 15, p. 716-727, 2015.

MORAIS, A. A. Avaliação de técnicas convencionais de tratamento de água para consumo humano na remoção de cianobactérias e cianotoxinas e processos oxidativos para remoção de microcistinas. Tese (Doutorado em Engenharia Civil) Universidade Federal de Viçosa. 178f, 2012.

MORITA, T.; ASSUMPÇÃO, R. M. V. Manual de soluções, reagentes e solventes: padronização, preparação, purificação, indicadores de segurança e descarte de produtos químicos. 2 ed. São Paulo: Ed Blucher, 675 p., 2007.

MÜLLER, C. C.; RAYA-RODRIGUEZ, M. T.; CYBIS, L. F. Adsorção em carvão ativado em pó para remoção de microcistina de água de abastecimento público. Engenharia Sanitária e Ambiental, v. 14, n 1, p. $29-28,2009$.

NEWCOMBE, G.; NICHOLSON, B. Treatment options for the saxitoxin class of cyanotoxins. Water Science and Technology: Water Supply, v. 2, n. 5-6, p. 271-275, 2004.

OLIVEIRA, A. C. P.; AZEVEDO, S. M. F. O. Avaliação da capacidade de adsorção e saturação de microcistinas por carvão ativado granular utilizados em sistema de purificação de água de centro de diálise. Jornal Brasileiro de Nefrologia, v. 26, n. 3, p. 121 - 128, 2004.

PARK, J.; JUNG, S.; YI, I.; CHOI, J.; KIM, S.; LEE, S. Adsorption of microcystin-LR on mesoporous carbons and its potential use in drinking water source. Chemosphere, v. 177, p. 15 -23, 2017.

PENDLETON, P.; SCHUMANN, R.; WONG, S. H. Mycrocystin-LR adsorption by activated carbon. Journal of Colloid and Interface Science, v. 240, p. 1-8, 2001.

RUIZ B.; CABRITA I.; MESTRE A.S.; PARRA J. B.; PIRES J.; CARVALHO A.P.; ANIA, C. O. Surface heterogeneity effects of activated carbons on the kinetics of paracetamol removal from aqueous solution. Appl Surf Sci. v. 256, 2010, p. $5171-5175$.

SANT'ANNA, C. L. AZEVEDO, M. T. P. AGUJARO, L. F. CARVALHO, M. C. CARVALHO, L. R. SOUZA, R. C. R. Manual ilustrado para 
identificação e contagem de cianobactérias planctônicas de águas continentais brasileiras. São Paulo: Editora Independência Ltda, 2006.

SILVA, G.G., NAVAL, L. P., DI BERNARDO, L., DANTAS, A. D. B. Tratamento de água de reservatórios por dupla filtração, oxidação e adsorção em carvão ativado granular. Engenharia Sanitária e Ambiental, v. 17, n. 1, p. 71-80, 2012.

SORLINI, S.; GIALDINI, F; COLLIVIGNARELLI, C. Removal of cyanobacterial cells and Microcystin-LR from drinking water using a hollow fiber microfiltration pilot plant. Desalination, v. 309, p.106 $-112,2013$.

SUN, F.; PEI, H., HU, W.; MA, C. The lysis of Microcystis aeruginosa in $\mathrm{AlCl} 3$ coagulation and sedimentation processes. Chemical Engineering Journal, v. 193 - 194, p. 296 - 202, 2012.

TEIXEIRA, M.R., ROSA, M.J. Comparing dissolved air flotation and conventional sedimentation to remove cyanobacterial cells of Microcystis aeruginosa. Part II. The effect of water background organics. Separation and Purification Technology, v. 53, p. 126-134, 2007.

TENG, W., WU, Z., FAN, J., CHEN, H., FENG, D., LV, Y., ZHAO, D. Ordered mesoporous carbons and their corresponding column for highly efficient removal of microcystin-LR. Energy Environ. Sci. 6, v. 6, n. 9, p. 2765-2776, 2013.

WARHURST, A. M.; McCONNACHIE, G. L.; POLLARD, S. J. T. Characterization and applications of activated carbon produced from moringa oleifera seed husk by syngle-step steam pirolysis. Water Research, v. 31, n. 4, p. 759-766, 1997.

ZAMYADI, A. et al. Species-dependence of cyanobacteria removal efficiency by different drinking water treatment processes. Water Research. v. 47. p. $2689-2700,2013$.

ZHANG, X., JIANG, L. Fabrication of novel rattle-type magnetic mesoporous carbon microspheres for removal of microcystins. J. Mater. Chem. v. 21, p. 10653-10657, 2011. 